\title{
INCLUSION OF GLUTATHIONE PEROXIDASE ON POLYPYRROLE MODIFIED ELECTRODE, TO BE ASSAYED AS GLUTATHIONE SENSOR
}

\author{
M. A. del VALLE *, Y-.Y. CHEN, A. ALARCÓN, A. RAMOS, L. A. HERNÁNDEZ, C. CANALES, B. GONZÁLEZ \\ Pontificia Universidad Católica de Chile, Facultad de Química, Av. V. Mackenna 4860, 7820436, Macul, Santiago, Chile. \\ (Received: May 18, 2013 - Accepted: August 21, 2013)
}

\begin{abstract}
In this work it was obtained a modified electrode by inclusion of the enzyme glutathione peroxidase (GPx) on a conductive polymer, polypyrrole (PPy), deposited on a graphite electrode (GC|PPy,GPx) for the amperometric detection of reduced glutathione (GSH) in presence of hydrogen peroxide. Also, working conditions were optimized in order to prepare the electrode $\mathrm{GC} \mid \mathrm{PPy}, \mathrm{GPx}$, which were tested for different concentrations of monomer and enzyme, electrochemical type of perturbance (by fixed potential or cyclic voltammetry) deposition potential and time (PPy film thickness, GPx), etc. by testing the response of the electrodes versus GSH in presence of hydrogen peroxide at physiological $\mathrm{pH}$ and temperature. At optimal experimental conditions, the achieved electrode gives a characteristic response for the analyte, which means that this modified electrode can be proposed as a selective GSH sensor, since it was shown that the enzyme maintains its activity during experimental manipulations and responds in a highly reproducible mode, so its use is proposed as an amperometric biosensor which is highly selective and stable.
\end{abstract}

Keywords: Polypyrrole, glutathione peroxidase, glutathione, polypyrrole, modified electrode.

\section{INTRODUCTION}

Glutathione is a non-proteic tripeptide that is present in most of mammalian cells in its reduced (GSH) and oxidized (GSSG) form ${ }^{1}$. GSH can be used as an indicator of some human diseases such as Alzheimer, Parkinson and Diabetes ${ }^{1-4}$, because qualitative and quantitative alterations of the GSH|GSSG ratio are considered as an indication of oxidative damage. In general, the redox cycle is a source of glutathione to protect against intracellular oxidative stress, which comprises two types of removing harmful compounds for the organism: 1) reduced glutathione acts as anti-oxidant, reacting with peroxides. This reaction is catalyzed by glutathione peroxidase; 2) soluble xenobiotic compounds are conjugated with glutathione to make them water-soluble and thus remove them from the body. Thus, glutathione peroxidase (GPx) is one of the enzymes, selenium-dependent type, which is involved on the transformation of reactive oxygen species, catalyzing the reduction of hydrogen peroxide $\left(\mathrm{H}_{2} \mathrm{O}_{2}\right)$ or lipoperoxide (L-OOH), using GSH as a reducing agent ${ }^{5,6}$.

Thus, this enzyme plays an important role in antioxidant defense, once it is located in all organs and tissues ${ }^{7}$. This explains the interest in developing methods to detect GSH and/or GSSG, which today include high performance liquid chromatography (HPLC) ${ }^{8}$, fluorimetry 9, chemiluminescence ${ }^{10}$, enzymatic recycling ${ }^{9}$, electrochemical techniques ${ }^{7,11}$, among others. Among these, the use of electrochemical methods is interesting because of its low cost, portability, high sensitivity, being these desirable characteristics for the electrochemical detection of GSH and/or GSSG. Therefore, now is in this discipline where major efforts are made in this respect and, particularly, the modified electrode with electrochemical methods for the determination of substrates have received increasing attention in recent years due to its simplicity, low cost, high detectability and easy miniaturization ${ }^{12-18}$.

Thus, there is a wide range of possibilities for the inclusion of receptors, since simple inclusion by adsorption, retention of receptor in a gel crosslinking polymer matrix, and the receivers together by bifunctional agents, to inclusion by covalent complex between receptor and the transducer, since the key is to have sufficiently selective recognition materials. Until now, synthetic receptors, in general, have a limited degree of recognition, which has been designed to consider transducers biological molecular recognition materials (bio-receptors), which are much more selective than synthetic type. However, one of the biggest problems in enzyme inclusion is to complete retention of biological activity and in addition, conventional methods - such as these suffer because of its poor reproducibility and great difficulty in controlling the reservoir in terms of space ${ }^{19}$. For this reason, it is more common to find included biomolecules in electro-polymerized films. Thus, the electrochemical formation of polymer layers of controlled thickness is an excellent method for obtaining a biosensor in an automatically (not manual) and reproducible way 20-22

It has proved that is possible to improve the selectivity of the sensors through the electrochemical formation of polymer layers and it has shown that the increasing of polymeric films active-layers provides better electrochemical signals compared to the unmodified electrode or electrodes coated with monolayers of sensitive materials ${ }^{23,24}$. The polymers used in the preparation of these films are conductive polymers, since only with them it is possible to regulate the film thickness. Among the most used polymers include polyaniline ${ }^{7}$, polypyrrole ${ }^{25,26}$, and polythiophene ${ }^{27}$ although polypyrrole is the most used one 28,29 .

Given the background described, the obtainment of a device which could identify the concentration of both GSH and GSSG, in vivo and in real time, it is proposed to develop an amperometric sensor, so it is postulated that, if there is an efficiently achievement on the inclusion of GPx enzyme on an electrodic substrate, it is possible to have a reduced glutathione selective biosensor which is useable under physiological conditions: when glutathione peroxidase is added to the electrolytic solution from which pyrrole is electro-polymerized, it may be included within the polymeric matrix which modifies the electrode, and should generate a current response due to its interaction with reduced glutathione. Thus, GPx would respond selectively versus GSH, which should be directly proportional to the amount of analyte with a sensitivity that depends on the amount of included enzyme and/or the deposited polymer thickness and area of the supporting electrode $20,30-33$.

In this paper the results obtained in the first stage of this study are presented, corresponding to the enzyme inclusion on polypyrrole modified electrode, where the response is determined versus its interaction with GSH, in order to project its possible use as amperometric sensor of this analyte.

\section{EXPERIMENTAL}

Electro-polymerization of pyrrole is carried out in conditions which are similar to those normally used to modify electrodes with polymeric deposit, but now the GPx enzyme is added in the electrolytic medium, in order to become included within the matrix polymer coated electrode, at the same time which the deposit is being generated.

In all the experiments have been used three-compartment electrochemical cell, anchor type, to a volume of approximately $20 \mathrm{~mL}$, and used pyrrole $98 \%$ Aldrich ${ }^{\circledR}\left(0.1 \mathrm{~mol} \cdot \mathrm{L}^{-1}\right)$ as a monomer, $\mathrm{KCl} 99.0 \% \mathrm{~m} / \mathrm{m}$ Merck $\left(0.5 \mathrm{~mol} \cdot \mathrm{L}^{-1}\right)$ as supporting electrolyte, $30 \% \mathrm{~m} / \mathrm{v} \mathrm{H}_{2} \mathrm{O}_{2}$, lyophilized glutathione peroxidase (stored at $-20{ }^{\circ} \mathrm{C}$ to ensure its preservation) and $98 \%$ reduced glutathione $(0.1$ mol $\cdot \mathrm{L}^{-1}$ ), acquired Aldrich ${ }^{\circledR}$, and $\mathrm{NaH}_{2} \mathrm{PO}_{4} \cdot \mathrm{H}_{2} \mathrm{O} 99.0 \% \mathrm{~m} / \mathrm{m}, \mathrm{Na}_{2} \mathrm{HPO}_{4} 99.0 \%$ $\mathrm{m} / \mathrm{m}$, purchased from Merck.

A graphite electrode in disc form $\left(0.2 \mathrm{~cm}^{2}\right.$ geometric area) was used as working electrode, which was mirror-polished with alumina $0.3 \mathrm{~mm}$ before each experiment. $\mathrm{An} \mathrm{Ag} \mid \mathrm{AgCl}$ wire immersed in a tetramethylammonium chloride solution, where its concentration is adjusted to the potential of a saturated calomel electrode, SCE, was used as the reference electrode ${ }^{34}$.

VoltaLab model with connection to PC electrochemical system was used for data acquisition (software SPEG) and PGZ 100 potentiostat.

The enzyme glutathione peroxidase (E 1.11.1.9) was reconstituted lyophilized diluting to $25 \mathrm{~mL}$ with phosphate buffer $(\mathrm{pH}$ 7.4) to obtain a 
solution which provides $4.0 \mathrm{EU} / \mathrm{mL}$ of enzyme (each unit of enzyme catalyzes the oxidation of $1.0 \mathrm{GSH}$ umol per minute in the presence of $\mathrm{H}_{2} \mathrm{O}_{2}, \mathrm{pH} 7.0$ and $25^{\circ} \mathrm{C}$ ) and then put into 50 Eppendorf of $0.5 \mathrm{~mL}$, so that each contributes with two EU.

The response of the graphite electrode (CG) supposedly modified by polypyrrole and enzyme (CG/PPy,GPx) was optimized for $\mathrm{pH}$ (7.4) and physiological temperature $\left(37^{\circ} \mathrm{C}\right)$ against $\mathrm{GSH}$, varying the thickness of the deposited film and electro-polymerization conditions (monomer concentration and enzyme, relationship between these concentrations, electrochemical perturbation, etc.). Furthermore, optimizing the concentration of peroxide within the physiological range, to ensure proper functioning of the enzyme. Thus, as optimal conditions to prepare the modified electrode (analyzing their response by cyclic voltammetry (CV) in $0.1 \mathrm{~mol} \cdot \mathrm{L}^{-1} \mathrm{GSH}$ and $100 \mathrm{~mL}$ of hydrogen peroxide solution, $\mathrm{H}_{2} \mathrm{O}_{2}$ ) are: electrolytic solution prepared by adding the contents of 3 Eppendorf (therefore, $6 \mathrm{EU}$ ) plus $0.1 \mathrm{~mol} \cdot \mathrm{L}^{-1}$ monomer (Py) and $0.5 \mathrm{~mol} \cdot \mathrm{L}^{-1} \mathrm{KCl}$ as supporting electrolyte, in phosphate buffer (PBS) $\mathrm{pH}$ $7.4,20^{\circ} \mathrm{C}$, perturbing by potentiostatic method (PM) at $0.6 \mathrm{~V}$ for $1 \mathrm{~min}$.

\section{RESULTS AND DISCUSSION}

In order to optimize the concentrations of monomer and enzyme in the electrolytic medium for the modification of the electrode, an electrolysis time optimization was done when it was worked with fixed potential (PM) or the number of voltammetric cycles when it was made by potentiodynamic method (CV), because these variables determine ultimately, the thickness of the film deposited on the electrode. As mentioned before, in each case it is measured the response in front of $\mathrm{GSH}$ and $\mathrm{H}_{2} \mathrm{O}_{2}$ at physiological $\mathrm{pH}$ and thus, it was determined the optimum conditions outlined in the experimental part.

Previously, it was found that regardless of the conditions of electrosynthesis, PPy modified electrodes (CG|PPy) give no response to GSH, so that they are not suitable to immobilize the enzyme. At the same time, the electrolytic medium employed, also suitable, because it does not interfere the response of the analyte of interest, since only residual current was obtained on electrodes modified with polymer (CG|PPy) or with the polymer and the "encapsulated" enzyme (GC|PPy,GPx), Figure 1.

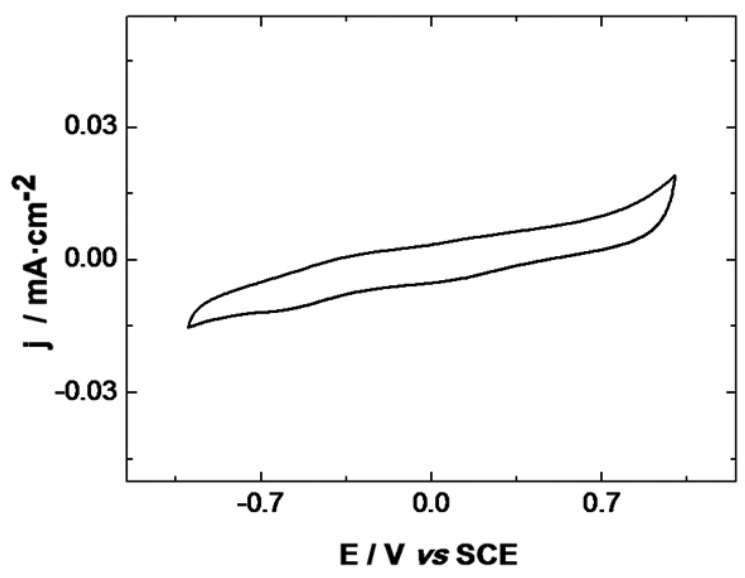

Figure 1. Voltammetric response of CG|Ppy, GPX in $100 \mathrm{uL}$ of $\mathrm{H}_{2} \mathrm{O}_{2}$ in 25 $\mathrm{mL}$ of PBS, $\mathrm{pH}=7.4$. Potential scan rate, $\mathrm{v}=50 \mathrm{mV} \cdot \mathrm{s}^{-1}$.

Thus, it was established that the optimum conditions described to prepare the modified electrode (GC|PPy,GPx) involve optimal concentrations of monomer and enzyme, and the type and conditions of electrochemical perturbation. This idea is based on previous studies that provide the necessary experience ${ }^{35}$, but do not negate these cumbersome measurements.

It is obtained, finally, in the best condition set here established (perturbation by fixed potential of $0.6 \mathrm{~V} v s$ SCE for $1 \mathrm{~min}$ in solution specified in the experimental section), an electrode which its electrochemical response shows that GPx enzyme maintains its activity despite being included in the polymer at physiological $\mathrm{pH}$ and temperature, which is manifested in the current response for GSH obtained by both electrochemical methods employed (CV or PM technique).

Figure 2 shows a current peak at a potential close to $0.3 \mathrm{~V} v s$ SCE and another, where the current is significantly higher, around $0.8 \mathrm{~V} v s \mathrm{SCE}$, and which would be attributable to the analyte. These results would account, first, that in presence of hydrogen peroxide, at physiological $\mathrm{pH}$ and temperature, the modified electrode could function as selective GPx sensor and secondly, that the enzyme maintains its activity during experimental manipulations performed here.

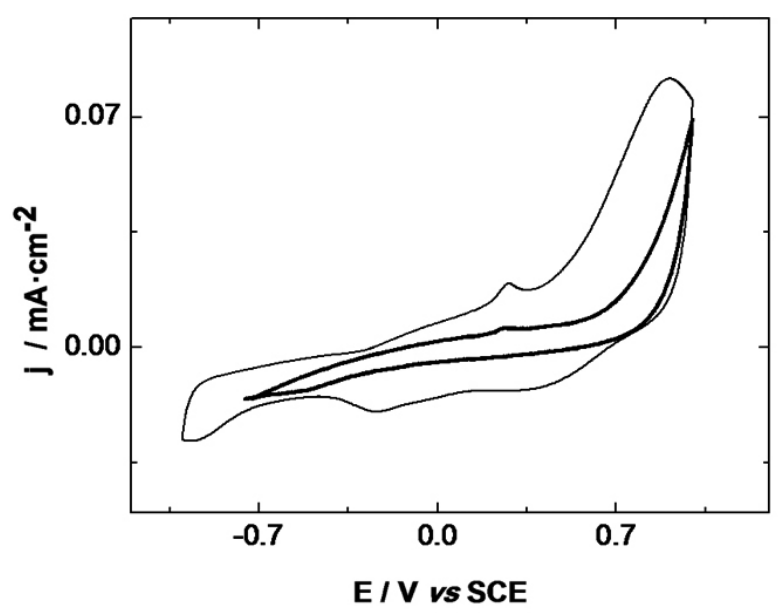

Figure 2. Voltammetric response of GC|Ppy,Gpx in GSH $0.1 \mathrm{~mol} \cdot \mathrm{L}^{-1}+$ $100 \mathrm{~mL}$ of $\mathrm{H}_{2} \mathrm{O}_{2}$ in $25 \mathrm{~mL}$ of PBS, $\mathrm{v}=50 \mathrm{mV} \cdot \mathrm{s}^{-1}$. In thick line: response under identical conditions, but in absence of GSH ("blank").

It is important to note that this response is exactly repeated each time that a new electrode is prepared at the same optimal conditions, which supports the obtainment of a reproducible and stable material. However, this does not occur when re-using the same electrode, since not always the same response is recovered, so that their application would be projected as a disposable electrode.

Anyway, before proposing its use as a biosensor, it is necessary to conduct the study on analytical detection limits, reproducibility, etc. However, the results obtained here are promising and can project the future with optimism and work in the next crucial stage, since the modified electrode is reached and which responds to GSH as it was proposed. Also, the enzyme ensures the selectivity, a fundamental variable for this purpose. Now its analytical behavior should be established, from this first study, more exploratory, this guarantees the feasibility of continuing in this way, which is an important area with great relevance today.

\section{CONCLUSIONS}

It is possible to include the enzyme GPx within the polymer matrix of PPy by Py electro-polymerization in the presence of the enzyme in the electrolytic medium in the experimental conditions used here.

The included enzyme retains its activity in the polymer, so that means that the modified electrode is very stable and has a reproducible response, as long as it is measured each time with a fresh electrode. For this reason, the development of their use as biosensor is proposed as a disposable electrode, which fortunately is feasible, given its low cost of production. Therefore, even if there is no analytical study, to be held in the near future, this first step allows proposing the modified electrode here prepared as GSH amperometric biosensor in situ, in presence of $\mathrm{H}_{2} \mathrm{O}_{2}$ and physiological conditions of $\mathrm{pH}$ and temperature, with the certainty that at least the sensor will have selective and highly reproducible response.

\section{DEDICATION}

This work is dedicated to Dr. Elsa Abuin (RIP), who was not only a great scientist, but also a great person.

\section{REFERENCES}

1. C. C. Corrêa, M. Santhiago, A. L. B. Formiga, L. T. Kubota, Electrochim. Acta 90, 309, (2013).

2. J. Ru, Du, D.-D. Qin, B.-M. Huang, Z.-H. Xue, X.-B. Zhou, X.-Q. Lu, 
Talanta 110, 15, (2013).

3. Y. Oztekin, A. Ramanaviciene, A. Ramanavicius, Electroanal. 23, 701, (2011).

4. X. Zhu, M. Hayashi, R. Subramanian, Chem. Res. Toxicol. 25, 1839, (2012).

5. R. Brigelius-Flohé, M. Maiorino, Biochim. Biophys. Acta (BBA) - Gral. Subj. 1830, 3289 (2013).

6. G. Passaia, L. Spagnolo Fonini, A. Caverzan, D. Jardim-Messeder, A. P. Christoff, M. L. Gaeta, J. E. de Araujo Mariath, R. Margis, M. MargisPinheiro, Plant Sci. 208, 93, (2013).

7. J. Narang, N. Chauhan, P. Jain, C. S. Pundir, Int. J. Biol. Macromol. 50, 672, (2012).

8. B. Ates, B. C. Ercal, K. Manda, L. Abraham, N. Ercal, Biomed. Chromat. 23, 119, (2009).

9. R. Irfan, K. Aruna, K. B. Saibal, Nat. Prot. 1, 3159, (2007)

10. H.-Y. Han, Z.-K. He, Y.-E. Zeng, Microchim. Acta 155, 431, (2006).

11. J. C. Harfield, C. Batchelor-McAuley, R. G. Compton, Analyst 137(10), 2285, (2012).

12. X. Wang, X. Chen, D. G. Evans, W. Yang, Sens. Act. B: Chem. 160, 1444, (2011).

13. G. Alfonso, M. A. del Valle, E. D. Borrego, G. M. Soto, M. E. Bodini, $J$. Chil. Chem. Soc. 49(2), 185, (2004).

14. F. Armijo, L. I. Canales, R. del Río, M. A. del Valle, J. Chil. Chem. Soc. 54(2), 158, (2009).

15. M. P. Miranda, R. del Río, M. A. del Valle, M. Faúndez, F. Armijo, J. Electroanal. Chem. 668, 1, (2012).

16. M. A. del Valle, D. Colomer, F. R. Diaz, L. A. Hernández, M. Antilén, M. A. Gacitúa, A. Ramos, G. C. Arteaga, J. Appl. Electrochem. 42(10), 867, (2012).

17. M. A. del Valle, F. Bustos, F. R. Díaz, G. C. Arteaga, L. A. Hernández, A. C. Ramos, Int. J. Sci. 2, 27, (2013).
18. L. Molero, M. Faúndez, M. A. del Valle, R. del Río, F. Armijo, Electrochim Acta 88, 871, (2013).

19. A. Sassolas, L. J. Blum, B. D. Leca-Bouvier, Biotech. Adv. 30, 489, (2012).

20. M. A. del Valle, D. Colomer, F. R. Díaz, L. Hernández, M. Antilén, M. Gacitúa, A. Ramos, G. C. Arteaga, J. Appl. Electrochem. 42, 867, (2012).

21. S. Nambiar, J. T. W. Yeow, Biosens. Bioelect. 26, 1825, (2011).

22. P. D’Orazio, Clin. Chim. Acta 412, 1749, (2011).

23. A. Ramanavicius, A. Finkelsteinas, H. Cesiulis, A. Ramanaviciene, Bioelectrochem. 79, 11, (2010).

24. A. Kausaite, A. Ramanaviciene, A. Ramanavicius, Polym. 50, 1846, (2009).

25. A. Ramanaviciene, A. Kausaite, S. Tautkus, A. Ramanavicius, J. Pharm. Pharmacol. 59, 311, (2007).

26. L. Liu, J. Liu, G. Bo, F. Yang, J. Crittenden, Y. Chen, J. Memb. Sci. 429, 252, (2013).

27. M. A. Rahman, D.-S. Park, S.-C. Chang, C. J. McNeil, Y.-B. Shim, Biosens. Bioelect. 21, 1116, (2006).

28. S. Cosnier, Biosens. Bioelect. 14, 443, (1999).

29. A. Ramanavičius, A. Ramanavičiene, A. Malinauskas, Electrochim. Acta 51, 6025, (2006).

39. G. C. Arteaga, M. Antilén, M. Faúndez, F. R. Díaz, F. Armijo, L. A. Hernández, A. Ramos, M. A. del Valle, Int. J. Electrochem. Sci. 8, 2898 , (2013).

31. M. Antilén, D. Guzmán, M. A. del Valle, R. del Río, M. V. Letelier, G. Lagos, M. Escudey, C. Pizarro, Int. J. Electrochem. Sci. 7, 5939, (2012).

32. G. C. Arteaga, M. A. del Valle, M. Antilén, M. Faúndez, M. A. Gacitúa, F. R. Díaz, J. C. Bernède, L. Cattin, Int. J. Electrochem. Sci. 6, 5209, (2011).

33. M. A. del Valle, G. M. Soto, L. Guerra, J. H. Vélez, F. R. Díaz, Polym. Bull. 51, 301, (2004)

34. G. East, M. A. del Valle, J. Chem. Ed. 77, 97, (2000).

35. M. A. del Valle, M. A. Gacitúa, L. I. Canales, F. R. Díaz, J. Chil. Chem. Soc. 54, 260, (2009). 